\title{
Anxiety and Worries among Pregnant Women during the COVID-19 Pandemic: A Multilevel Analysis
}

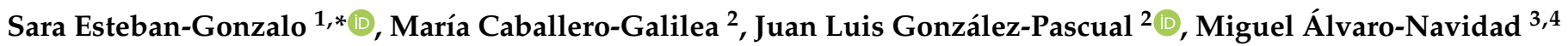 \\ and Laura Esteban-Gonzalo ${ }^{2,5}$
}

check for

updates

Citation: Esteban-Gonzalo, S.

Caballero-Galilea, M.

González-Pascual, J.L.;

Álvaro-Navidad, M.;

Esteban-Gonzalo, L. Anxiety and

Worries among Pregnant Women

during the COVID-19 Pandemic: A

Multilevel Analysis. Int. J. Environ.

Res. Public Health 2021, 18, 6875

https://doi.org/10.3390/

ijerph18136875

Academic Editors: Rubén López-Bueno,

Yasmín Ezzatvar, Guillermo Felipe

López Sánchez and Lee Smith

Received: 24 May 2021

Accepted: 24 June 2021

Published: 26 June 2021

Publisher's Note: MDPI stays neutra with regard to jurisdictional claims in published maps and institutional affiliations.

Copyright: (c) 2021 by the authors. Licensee MDPI, Basel, Switzerland This article is an open access article distributed under the terms and conditions of the Creative Commons Attribution (CC BY) license (https:// creativecommons.org/licenses/by/ $4.0 /)$
1 Psychology Department, Faculty of Biomedicine, Universidad Europea de Madrid, 28670 Madrid, Spain

2 Nursing Department, Faculty of Biomedicine, Universidad Europea de Madrid, 28670 Madrid, Spain; maria.caballero@universidadeuropea.es (M.C.-G.); juanluis.gonzalez2@universidadeuropea.es (J.L.G.-P.); lesteb05@ucm.es (L.E.-G.)

3 Obstetrics and Gynecology Department, Faculty of Medicine, Universidad Autónoma de Madrid, 28049 Madrid, Spain; malvaro@fjd.es

4 Department of Obstetrics and Gynecology, Hospital Universitario Fundación Jiménez Díaz, 28040 Madrid, Spain

5 Nursing Department, Faculty of Nursing, Physiotherapy and Podiatry, Universidad Complutense de Madrid, 28040 Madrid, Spain

* Correspondence: sara.esteban.gonzalo@gmail.com; Tel.: +34-639-377-412

Abstract: Background. Several studies have identified pregnant women as a vulnerable group during the COVID-19 pandemic. The perinatal period has been identified as a stage of great risk for the mental health of pregnant women, due to a large increase in mental pathologies during this period. In this context, the objective of the present study was to assess the associations between socioeconomic and demographic factors, health concerns and health information management, and anxiety level during the COVID-19 pandemic in pregnant Spanish women. Method. The sample of this crosssectional study was comprised of 353 pregnant women, aged 18 or older and residing in Spain. Data collection was carried out from 1 June to 30 September 2020. Participants were recruited from Quirónsalud University Hospital of Madrid. Multilevel regression models were built to value the associations between demographic factors, health concerns and health information management, and anxiety level during the COVID-19 pandemic among pregnant women. Results. Reduced working hours and income due to the COVID-19 pandemic were related to increased anxiety levels, as was the level of concern about COVID-19 symptoms, potential complications, contagion and consequences for the baby. Worries caused by restrictive measures adopted against COVID-19 and resulting isolation, delivery, postpartum and breastfeeding were also associated with increased anxiety levels. Being a separated or divorced woman and being informed to a greater extent by a midwife were related to lower anxiety levels. An increase in the degree of information obtained about COVID-19 symptoms, complications, contagion and consequences for the baby, restrictive measures and isolation adopted against COVID-19, delivery, postpartum and breastfeeding, were also related to decreased anxiety levels. Conclusions. The most vulnerable future mothers in terms of anxiety levels are those with reduced working hours and income due to the COVID-19 pandemic, those with a higher level of concern and who had access to a lesser degree of information about COVID-19 (symptoms and complications, contagion and consequences on the baby, restrictive measures and isolation, delivery, postpartum and breastfeeding), as well as pregnant women who have obtained information about COVID-19 during pregnancy from TV.

Keywords: anxiety; worries; pregnancy; COVID-19; Spain

\section{Introduction}

The public health consequences of the COVID-19 pandemic have been devastating [1,2]. The number of deaths from COVID-19 has reached unimaginable numbers. Currently, 
3.42 million people have died and 165 million have been infected worldwide to date because of the virus (3.63 million of infected people and 79,568 deaths in Spain). In addition, the health of the uninfected population has also been seriously affected. Specifically, the negative consequences for mental health are still incalculable, with an upward trend in the risk of manifesting a variety of pathologies [3-5]. Drastic changes in people's lifestyles have seriously impacted their way of life [6-8]. Social and mobility restrictions, quarantine periods and lockdowns have forced the population into strict isolation conditions $[9,10]$. In addition to fear of the virus itself, the uncertainty generated by the closure of educational centers, services, stores, and many other businesses has caused a social and economic crisis, seriously affecting people's mental health and significantly increasing the risk of reporting mental pathologies [11-13].

Many studies have yielded important data on how these aspects have influenced the manifestation of psychological distress. For instance, some have emphasized the importance of certain sociodemographic variables and identified groups of greater vulnerability. According to previous studies, more vulnerable populations in terms of mental health during the COVID-19 outbreak were found to be women, younger people, people with basic or medium studies, students and individuals with no remunerated activities, single populations and those co-living with dependent seniors as well as those with a reduced number of children [13-15]. Other factors, such as pre-existing physical and mental health conditions and low social support, have been linked to depressive symptoms [16]. Information received, prevention measures, beliefs, concerns, and the population's knowledge about COVID-19 have also been associated with psychological health [17].

\section{Pregnant Women during COVID-19 Pandemic}

Several studies have identified women as a vulnerable group during the COVID-19 pandemic $[13,18,19]$. Numerous studies have found higher levels of stress, anxiety, depression, and post-traumatic stress disorder among women, when compared to men $[18,20,21]$. In addition, an increased risk of family violence during the COVID-19 pandemic has been observed [18]. Other factors of social vulnerability must also be taken into account. Lack of social support and isolation have contributed negatively to the mental health status of women [19]. In many cases, household and childcare tasks have been delegated to women in a more pronounced way, increasing pre-existing levels of stress and anxiety [20-22].

Pregnancy and postpartum mental illnesses include depression, anxiety disorders, and postpartum psychosis, which usually manifests as bipolar disorder [23]. Perinatal depression and anxiety are common [24]. Long-term psychiatric complications of pregnancy and postpartum mental illness include unipolar major depression, bipolar depression and obsessive-compulsive symptoms, among others [25]. Psychological, social, behavioral, biological and environmental forces shape mental disorders during the perinatal period, but also provide a window into a woman's long-term health [26,27]. Sleep deprivation, hormonal changes and the pressure of caring for a new infant may enhance the development of pregnancy and postpartum mental illness and unmask a psychological vulnerability leading to psychiatric disease later in life [25].

Several studies have investigated women's mental health during the COVID-19 pandemic [28-32]. Given the importance of stressors on the mental health of women in the perinatal period, this group is presented as one of high risk for developing a variety of psychopathologies [19]. Stressors during the COVID-19 period for pregnant women have been numerous. For example, restrictions in hospitals have led many women to make the decision to give birth at home, exposing them to risks such as complications in childbirth without adequate care [29]. Although transmission of SARS-COV-2 through breast milk is not common, some women have decided not to breastfeed their babies to reduce the risk of infection $[33,34]$. The virus containment measures enacted by governments have increased feelings of isolation, confusion and anxiety in an already vulnerable population $[29,35]$. Economic and financial uncertainties may have worsened feelings of uncertainty, thus increasing pregnant women's vulnerability even more [29]. 
According to recent studies carried out in Europe, the prevalence of depressive symptoms in pregnancy and postpartum was explicitly higher compared to data obtained prior to the pandemic [36]. Longitudinal studies in Spain have observed a gradual increase in psychopathological indicators and a decrease in positive affect among pregnant women during the strict lockdown period [30]. Studies conducted in China have shown an increase in self-harm thoughts, and in depressive symptoms positively associated with the number of newly-confirmed cases of coronavirus, suspected infections, and deaths per day [37,38]. Some associated risk factors of mental illness among pregnant women were isolation and loneliness [39], stress and loss of income and violence at home, among others [40-42].

The results regarding the sociodemographic correlates that could exacerbate psychological distress in pregnant women are not conclusive. For instance, in studies carried out in Argentina and China, no significant differences in the risk of psychological distress seemed to have been observed in relation to age, socioeconomic status, educational level, number of children, and dwelling size [30,43]. In contrast, other studies carried out in China did find a relationship between these same variables and the mental health of pregnant women, emphasizing the protective factors of age, education and a well-paid occupation for their mental health [44]. Other studies carried out in the United States have found that income loss due to the pandemic and being a woman of color were associated with greater levels of stress [45]. In addition, the same authors found that access to outdoor space and an older age were protective factors against stress [45].

Health concerns should not be underestimated either. Health concerns for oneself or one's infant, such as accessibility to health services, availability of transportation, or the absence of tests to monitor infant health, seem to have taken on an inestimable influence on women's mental health concerns [46-48]. The number of children born, complication during pregnancy, availability of prenatal care services, and use of social media for obtaining health information were factors associated to pregnant women's mental health [44]. In addition, the way in which the COVID-19 pandemic is experienced should also be highlighted. Loneliness and feelings of vulnerability such as fear of infection, uncontrollable stress and perceiving unpredictable environments-including economic and health stressors-may also contribute to poorer women's psychological health [49].

Therefore, taking into account the evidence provided by the aforementioned studies, indicating significant vulnerability of pregnant women in terms of mental health, our research question is aimed at detecting the factors that may influence anxiety levels of pregnant women living in Spain during the COVID-19 pandemic. Thus, the objective of the present study was to identify those socioeconomic, demographic, health-related and information management factors and concerns that may influence the anxiety level of pregnant women during the COVID-19 pandemic.

\section{Method}

\subsection{Study Design and Participants}

This is a cross-sectional study designed to value the associations between social and demographic factors, health concerns and health information management, and anxiety level of pregnant women in Spain during the COVID-19 pandemic.

Participants were recruited from the Quirónsalud University Hospital of Madrid. This hospital leads the initiative of offering pregnant women the possibility of subscribing to a monthly newsletter that provides them health information about each stage of their pregnancy. Other hospitals have joined this initiative. Among them, the Jiménez Díaz Foundation University Hospital and San José Quirónsalud Hospital also decided to collaborate in the present study. After obtaining permission from each institution, complete information on the study was provided in the newsletter. Women who accepted to participate in the study had access to the anonymous questionnaire and were recruited through a consecutive convenience sample.

Inclusion criteria were to be pregnant, to be 18 years or older, to reside in Spain, to be able to fill out the Spanish questionnaire and to provide written informed consent. Data 
were collected between 1 June and 30 September 2020, a period during which Spain, among many other countries, was fighting against the COVID-19 pandemic.

A total of 453 women completed the questionnaire, of which, 45 women had already given birth to their babies and were excluded. Of the remaining 408 women, 353 presented valid data about their anxiety level and were included in the analysis. The sample size was calculated for a linear regression using the G-Power tool, considering an Alpha error of 0.05 and a 0.95 statistical power, resulting in a minimum sample size of 262 women. Post hoc statistical power calculations were also carried out, for an Alpha error of 0.05 and according to the effect size range obtained in the models (considering the three predictors used), which showed a statistical power higher than 0.95 in all cases.

\subsection{Measurement Instruments}

\subsubsection{Anxiety Level}

The dependent variable, anxiety level, was assessed using the State Trait Anxiety Inventory (STAI). This tool was employed for three different reasons. First, it has been commonly used in relevant studies, widely cited in the literature and adapted for use in a large number of countries [50]. Second, it is a well-documented scale capable of diagnosing anxiety in clinical settings and can be used to detect distress. Third, the Spanish adaptation has shown adequate psychometric properties, with a Cronbach's alpha reliability of 0.90 for Trait and 0.94 for State Anxiety, and has also been sensitive to increased environmental stimuli that produce stress [51]. In the present study, only STAI state (STAI-S) was used due to limitations in the length of the questionnaire. It is composed of 20 items with a 4-point scale ( $0-3$ points) and a final score between 0 and 60 . A higher score corresponds to increased anxiety level [52].

\subsubsection{Socioeconomic and Demographic Factors}

Several socioeconomic and demographic conditions have been considered independent variables:

- Number of previous children were reported as a number by the participants.

- Country of origin was collected using a single question: what is your country of origin? (Spain/other).

- Area of residence was determined from the city code referred by the participants. Each area of residence was dichotomized in rural or urban area of residence according to the National Institute of Statistics definition (urban areas those with more than 10,000 inhabitants and rural areas with less) [53].

- Level of education was reported as basic level of studies (primary and secondary school), medium level (baccalaureate and technical education) and high level (university studies). - Marital status was reported by the participants as: married, single, unmarried partner, separated/divorced and widowed. No widowed women were identified; thus, this category will not be included in the tables and results section.

- Employment status during the COVID-19 pandemic was referred by the participants as: self-employment, employment, unemployment, homemaker, or student. No students were detected.

- To have lost one's job/have reduced working hours/have reduced income due to the COVID-19 pandemic was reported as yes or no through the following questions: Have you lost your job/Have your working hours been reduced/Has your salary been reduce due to the COVID-19 pandemic?

\subsubsection{Pregnancy-Related Factors}

The following factors associated with the gestation period have been taken into account as independent variables:

- Trimester of pregnancy was reported as first, second or third.

- Week of pregnancy was referred as a number by the participants.

- Primiparous women were considered those who reported no previous children. 


\subsubsection{Health-Related Concerns}

The participants were asked to rate from 1 to 5 their level of concern about: COVID-19 symptoms and complications of the sickness, contagion and consequences on the baby, restrictive measures and isolation adopted against COVID-19, delivery, and postpartum and breastfeeding.

\subsubsection{Health Information-Related Factors}

On the one hand, participants were asked where they obtained information with the following question: Where did you look for or obtain information about COVID 19 and pregnancy? Please point out those answers that are most relevant. Possible answers were: health professionals they were treated by, hospital obstetric newsletter, hospital obstetric web page, official sources of information (for example information provided by the Spanish Ministry of Health or the government), internet, social networks, family and friends and TV. Each woman was able to choose as many answers as she considered appropriate. Based on this information, eight different variables were constructed, one for each response category. All of them were dichotomous (yes/no), referring to whether each participant obtained or sought information from each potential source.

On the other hand, each participant was asked to rate from 1 to 5 the level of information they obtained about: COVID-19 symptoms and complications of the sickness, contagion and consequences on the baby, restrictive measures adopted against COVID-19 and resulting isolation, delivery, and postpartum and breastfeeding. As a result, five separate variables were considered as to the degree of information available to the participants on each item assessed.

Health professionals who provide information were also reported: gynecologist, midwife, nurse or other (administrative staff, pharmaceutical, etc). In this regard, four dichotomous variables (yes/no) were available for analysis, based on whether each participant obtained information from each of the specified professionals.

Finally, the level of satisfaction with the information provided by health workers, and with the empathy shown while informing, was rated from 1 to 5 by participants. Therefore, two variables were considered. The first variable refers to the degree of satisfaction with the information provided by the professional(s) previously specified, regardless of the professional from whom the information was obtained. The second was based on the degree of empathy shown by the professional(s) who provided the information.

All these variables have been considered independent variables.

\subsection{Co-Variates}

Additionally, age and medical COVID-19 diagnosis were considered co-variates in the analyses performed. Medical COVID-19 diagnosis (yes/no) was assessed asking participants if they had a positive COVID-19 test. Age was referred as a number by each participant. Both variables were included as co-variates for the analysis, given their relevance and potential influence on anxiety level.

\subsection{Ethical Procedures}

The protocol for the present study obtained approval from the Ethics Committee of the Jiménez Díaz Foundation Hospital (E0070-20_HUQM). All institutions and participants were informed of the purpose and intent of the study and provided written consent. Similarly, anonymity of each of the participants was ensured.

\subsection{Data Analyses}

All statistical analysis was conducted using the Statistical Package for the Social Sciences software version 21.0 (SPSS. Inc., Chicago, IL, USA) and STATA/SE 14.1 software (Stata Corp LP, College Station, TX, USA).

Descriptive statistics (mean values and standard deviations or numbers and percentages) were calculated to describe participant characteristics. Differences between 
categorical variables and anxiety score were assessed using the Mann-Whitney U test for dichotomous variables and the Kruskal-Wallis test for variables with more than two categories. The Spearman correlation test was employed to value associations between quantitative variables and STAI-S scores after assessing the distribution of each variable using the Kolmogorov-Smirnov test (all, $p<0.001$ ).

Multilevel linear regression was used to test the association between social and demographic factors, health concerns and health information-related variables, and STAI-S score. Non-parametric variables were transformed to address normality. All models included a random intercept for the hospital where the participant was recruited. First, unadjusted models were constructed to assess the influence of each of the independent variables studied on the dependent variable (anxiety levels). Secondly, it was considered necessary to adjust the models for two variables that could influence the anxiety levels of the participants, in order to give greater validity to the results obtained in this study. The first of these was age. The second was having a medical diagnosis of COVID-19, although very few participants were included in this variable. These variables were included one by one in the models constructed. Since neither of these two variables represented a significant variation in the results, a single model adjusted for both variables was constructed, and only adjusted models will be described in the results section.

\section{Results}

Mean and standard deviation (SD) values of the STAI-S, as well as characteristics of the participants, are presented in Table 1. Pregnant women showed a mean score of 24.6 (10.4 SD). Of the women examined, 2.5\% had a medical COVID-19 diagnosis, a status that was not associated to STAI-S score.

Table 1. Characteristics of the participants examined and bivariate analyses between STAI-S score and socioeconomic and demographic factors, pregnancy-related factors, health-related concerns and health information-related factors.

\begin{tabular}{|c|c|c|c|}
\hline $\mathbf{n}$ & 353 & STAI-S Score & $\mathrm{p}^{\mathrm{a}}$ \\
\hline STAI-S score (0-60) [mean (SD)] & $24.6(10.4)$ & & \\
\hline Positive COVID-19 test $(\%)$ & & & $0.563^{\#}$ \\
\hline Yes & 2.5 & $25.6(6.8)$ & \\
\hline No & 97.5 & $24.5(10.4)$ & \\
\hline Age [mean (SD)] & $35.9(7.0)$ & & $0.654(-0.02)^{x}$ \\
\hline \multicolumn{4}{|c|}{ Socioeconomic and demographic variables } \\
\hline Country of origin (\%) & & & $0.780^{\#}$ \\
\hline Spain & 90.7 & $24.6(10.4)$ & \\
\hline Other & 9.3 & $24.4(10.0)$ & \\
\hline Area of residence $(\%)$ & & & $0.099^{\#}$ \\
\hline Urban area & 94.0 & $24.8(10.4)$ & \\
\hline Rural area & 6.0 & $20.9(9.6)$ & \\
\hline Level of education (\%) & & & $0.129 *$ \\
\hline Basic level of studies & 3.0 & $26.1(7.0)$ & \\
\hline Medium level of studies & 13.0 & $27.0(10.5)$ & \\
\hline High level of studies & 84.0 & $24.1(10.4)$ & \\
\hline Marital status & & & $0.027 *$ \\
\hline Married & 66.6 & $25.1(10.3)$ & \\
\hline Single & 22.1 & $24.6(10.0)$ & \\
\hline Unmarried partner & 7.4 & $23.3(11.7)$ & \\
\hline Separated/divorced & 3.9 & $16.6(6.6)$ & \\
\hline Employment status (\%) & & & $0.771 *$ \\
\hline Self-employment & 9.6 & $24.4(9.8)$ & \\
\hline Employment & 83.0 & $24.4(10.5)$ & \\
\hline Unemployment & 5.1 & $25.5(9.6)$ & \\
\hline Homemaker & 2.3 & $27.8(10.3)$ & \\
\hline
\end{tabular}


Table 1. Cont.

\begin{tabular}{|c|c|c|c|}
\hline $\mathbf{n}$ & 353 & STAI-S Score & $p^{a}$ \\
\hline To have lost one's job b (\%) & & & $0.156^{\#}$ \\
\hline Yes & 5.1 & $28.3(10.9)$ & \\
\hline No & 94.9 & $24.3(10.3)$ & \\
\hline Reduced working hours ${ }^{\mathrm{b}}(\%)$ & & & $0.005 \#$ \\
\hline Yes & 20.4 & $27.8(10.9)$ & \\
\hline No & 79.6 & $23.7(10.1)$ & \\
\hline Reduced income ${ }^{b}(\%)$ & & & $0.025 \#$ \\
\hline Yes & 30.9 & $26.4(10.8)$ & \\
\hline No & 69.1 & $23.7(10.1)$ & \\
\hline Number of previous children [mean (SD)] & $0.3(0.5)$ & & $0.109(0.08)^{x}$ \\
\hline \multicolumn{4}{|l|}{ Pregnancy-related factors } \\
\hline Primiparous women $(\%)$ & & & $0.119^{\#}$ \\
\hline Yes & 23.2 & $25.9(10.2)$ & \\
\hline No & 76.8 & $24.1(10.4)$ & \\
\hline Trimester of pregnancy (\%) & & & $0.716^{*}$ \\
\hline First & 19.2 & $25.1(10.6)$ & \\
\hline Second & 38.4 & $24.1(10.8)$ & \\
\hline Third & 42.4 & $24.7(9.9)$ & \\
\hline Week of pregnancy [mean (SD)] & $24.9(9.3)$ & & $0.462(-0.03)^{x}$ \\
\hline \multicolumn{4}{|l|}{ Health-related concerns } \\
\hline Level of concern about: (1-5) [mean (SD)] & & & \\
\hline COVID-19 symptoms and complications & $4.1(1.0)$ & & $<0.001(0.28) x$ \\
\hline Contagion and consequences on the baby & $4.5(0.9)$ & & $0.001(0.18) x$ \\
\hline Restrictive measures and isolation & $3.3(1.1)$ & & $0.001(0.18) x$ \\
\hline Delivery & $4.2(1.0)$ & & $<0.001(0.24) x$ \\
\hline Postpartum and breastfeeding & $4.0(1.0)$ & & $<0.001(0.22) x$ \\
\hline \multicolumn{4}{|l|}{ Health information-related factors } \\
\hline \multicolumn{4}{|l|}{$\begin{array}{l}\text { Degree of information you have about: (1-5) } \\
\text { [mean (SD)] }\end{array}$} \\
\hline COVID-19 symptoms and complications & $2.6(1.2)$ & & $0.001(-0.16) x$ \\
\hline Contagion and consequences on the baby & $2.5(1.3)$ & & $0.001(-0.17) x$ \\
\hline Restrictive measures and isolation & $3.3(1.3)$ & & $0.006(-0.14) x$ \\
\hline Delivery & $2.4(1.3)$ & & $0.007(-0.14) x$ \\
\hline Postpartum and breastfeeding & $2.2(1.3)$ & & $<0.001(-0.18) \times$ \\
\hline \multicolumn{4}{|l|}{$\begin{array}{l}\text { Have obtained information about COVID-19 during } \\
\text { pregnancy from: }(\%)\end{array}$} \\
\hline Health professionals & 36.0 & $24.9(9.7)$ & 0.615 \\
\hline Hospital obstetric newsletter & 19.5 & $24.4(10.4)$ & $0.778^{\#}$ \\
\hline Hospital obstetric web page & 15.6 & $23.2(9.5)$ & $0.409^{\#}$ \\
\hline Official sources of health information & 25.2 & $23.6(10.1)$ & $0.524^{\#}$ \\
\hline Internet & 72.8 & $25.0(10.2)$ & $0.113^{\#}$ \\
\hline Social networks & 31.4 & $26.0(9.9)$ & $0.064^{\#}$ \\
\hline Family and friends & 19.5 & $25.1(10.2)$ & $0.582 \#$ \\
\hline $\mathrm{Tv}$ & & & $0.014^{\#}$ \\
\hline Yes & 23.5 & $26.8(9.8)$ & \\
\hline No & 76.5 & $23.8(10.4)$ & \\
\hline $\begin{array}{c}\text { Health professional who has provided the most } \\
\text { information: }(\%)\end{array}$ & & & 0.204 * \\
\hline Gynecologist & 45.9 & $24.7(10.4)$ & \\
\hline Midwife & 20.1 & $22.1(9.5)$ & \\
\hline Nurse & 4.0 & $23.7(9.1)$ & \\
\hline Other & 13.0 & $26.2(9.9)$ & \\
\hline
\end{tabular}


Table 1. Cont

\begin{tabular}{|c|c|c|c|}
\hline $\mathbf{n}$ & 353 & STAI-S Score & $\mathrm{p}^{\mathrm{a}}$ \\
\hline $\begin{array}{c}\text { Satisfaction with information provided by health } \\
\text { professionals (1-5) [mean (SD)] }\end{array}$ & $2.9(1.2)$ & & $<0.001(-0.18) \times$ \\
\hline $\begin{array}{l}\text { Satisfaction with empathy showed by professionals } \\
\text { when informed (1-5) [mean (SD)] }\end{array}$ & $3.6(1.2)$ & & $<0.001(-0.23)$ \\
\hline
\end{tabular}

$p^{a}$ value for comparing variables studied and STAI-S score. ${ }^{\times}$Spearman correlation test, $p$ (correlation coefficient). \# U-Mann-Withney test.

${ }^{*}$ Kruskal-Wallis test. ${ }^{\mathrm{b}}$ Due COVID-19. Bold: $p \leq 0.05$

\subsection{Socioeconomic and Demographic Factors}

The STAI-S score was higher in women who have reduced working hours $(27.8+/-10.9$, $p=0.005)$ and income $(26.4+/-10.8, p=0.025)$ due to the COVID-19 pandemic, and lower in separated or divorced women $(16.6+/-6.6, p=0.027)$,

\subsection{Health-Related Concerns}

The STAI-S score was higher in women with an increasing level of concern about COVID-19 symptoms and complications from the sickness $(p<0.001, r=0.28)$, contagion and consequences on the baby $(p=0.001, r=0.18)$, restrictive measures and isolation adopted against COVID-19 $(p=0.001, r=0.18)$, delivery $(p<0.001, r=0.24)$, and postpartum and breastfeeding $(p<0.001, r=0.22)$.

\subsection{Health Information-Related Factors}

The STAI-S score was lower in women with a greater degree of information about COVID-19 symptoms and complications of the sickness ( $p=0.001, r=-0.16)$, contagion and consequences for the baby $(p=0.001, r=-0.17)$, restrictive measures and isolation adopted against COVID-19 $(p=0.006, r=-0.14)$, delivery $(p=0.007, r=-0.14)$, and postpartum and breastfeeding $(p<0.001, r=-0.18)$. Women with a higher satisfaction level with the information provided by health professionals $(p<0.001, r=-0.18)$ and with the empathy shown by health professionals when informing $(p<0.001, r=-0.23)$ also showed a lower STAI-S score. However, the STAI-S score was higher in women who reported obtaining information about COVID-19 and pregnancy from TV $(26.8+/-9.8, p=0.014)$.

Multilevel linear regression models for the STAI-S score are shown in Table 2. As previously mentioned, since no relevant differences were detected between the unadjusted model and the adjusted model, only the results associated with the adjusted model will be shown in this section.

Table 2. Multilevel linear regression models for STAI-S score $(n=353)$.

\begin{tabular}{|c|c|c|c|c|c|c|c|}
\hline \multirow{2}{*}{ Title } & \multicolumn{4}{|c|}{ Unadjusted Model } & \multicolumn{3}{|c|}{ Adjusted Model } \\
\hline & $n$ & $\beta(\mathrm{SE})$ & $95 \%$ CI & $p$ & $\beta(\mathrm{SE})$ & $95 \%$ CI & $p$ \\
\hline \multicolumn{8}{|c|}{ Socioeconomic and demographic variables } \\
\hline Country of origin & 353 & & & & & & \\
\hline Other than Spain & & $-0.14(1.89)$ & $-3.86-3.57$ & 0.940 & $-0.02(1.09)$ & $-3.99-3.47$ & 0.892 \\
\hline Area of residence & 352 & & & & & & \\
\hline Rural area & & $-3.86(2.33)$ & $-8.42-0.70$ & 0.098 & $-3.82(3.33)$ & $-8.38-0.74$ & 0.101 \\
\hline Level of education & 351 & & & & & & \\
\hline Basic level of studies & & $1.63(3.04)$ & $-4.33-7.61$ & 0.591 & $1.55(3.05)$ & $-4.42-7.53$ & 0.610 \\
\hline Medium level of studies & & $2.82(1.63)$ & $-0.37-6.03$ & 0.083 & $2.83(1.63)$ & $-0.37-6.04$ & 0.084 \\
\hline High level of studies & & $-2.97(1.50)$ & $-5.92-0.01$ & 0.049 & $-2.96(1.51)$ & $-5.93-0.00$ & 0.050 \\
\hline Marital status & 353 & & & & & & \\
\hline Married & & $1.78(1.16)$ & $-0.50-4.06$ & 0.127 & $1.70(1.17)$ & $-0.59-4.00$ & 0.146 \\
\hline Single & & 0.05 (1.33) & $-2.55-2.66$ & 0.966 & $0.18(1.34)$ & $-2.44-2.81$ & 0.889 \\
\hline Unmarried partner & & $-1.33(2.11)$ & $-5.47-2.80$ & 0.527 & $-1.32(2.11)$ & $-5.46-2.81$ & 0.531 \\
\hline Separated/divorced & & $-8.26(2.79)$ & $-13.74-2.78$ & 0.003 & $-8.33(2.79)$ & $-13.82-2.84$ & 0.003 \\
\hline Employment status & 353 & & & & & & \\
\hline Self-employment & & $-0.19(1.87)$ & $-3.86-3.48$ & 0.919 & $-0.28(1.87)$ & $-3.96-3.39$ & 0.880 \\
\hline Employment & & $-0.74(1.47)$ & $-3.62-2.13$ & 0.613 & $-0.65(1.48)$ & $-3.55-2.25$ & 0.661 \\
\hline Unemployment & & $0.96(2.51)$ & $-3.95-5.88$ & 0.701 & $0.92(2.51)$ & $-3.99-5.85$ & 0.711 \\
\hline
\end{tabular}


Table 2. Cont.

\begin{tabular}{|c|c|c|c|c|c|c|c|}
\hline \multirow{2}{*}{ Title } & \multicolumn{4}{|c|}{ Unadjusted Model } & \multicolumn{3}{|c|}{ Adjusted Model } \\
\hline & $n$ & $\beta$ (SE) & $95 \% \mathrm{CI}$ & $p$ & $\beta$ (SE) & $95 \% \mathrm{CI}$ & $p$ \\
\hline Homemaker & & $3.36(3.70)$ & $-3.89-10.63$ & 0.364 & $3.31(3.79)$ & $-4.12-10.75$ & 0.382 \\
\hline To have lost one's job ${ }^{a}$ & 353 & $4.00(2.50)$ & $-0.89-8.91$ & 0.109 & $3.95(2.50)$ & $-0.95-8.86$ & 0.114 \\
\hline Reduced working hours ${ }^{a}$ & 353 & $4.09(1.35)$ & $1.44-6.75$ & 0.002 & $4.07(1.35)$ & $1.42-6.72$ & 0.003 \\
\hline Reduced income ${ }^{a}$ & 353 & $2.72(1.18)$ & $0.39-5.05$ & 0.022 & $2.66(1.19)$ & $0.32-5.00$ & 0.025 \\
\hline Number of previous children & 353 & $1.30(1.00)$ & $-0.65-3.27$ & 0.191 & $1.42(1.04)$ & $-0.62-6.47$ & 0.174 \\
\hline \multicolumn{8}{|l|}{ Pregnancy-related factors } \\
\hline Primiparous women & 353 & $1.82(1.30)$ & $-0.72-4.38$ & 0.161 & $1.93(1.30)$ & -0.62 .4 .50 & 0.139 \\
\hline Trimester of pregnancy & 353 & & & & & & \\
\hline First & & $0.71(1.40)$ & $-2.02-3.46$ & 0.609 & $0.67(1.40)$ & $-2.06-3.42$ & 0.628 \\
\hline Second & & $-0.74(1.13)$ & $-2.96-1.48$ & 0.514 & $-0.74(1.14)$ & $-2.98-1.50$ & 0.518 \\
\hline Third & & $0.26(1.11)$ & $-1.92-2.45$ & 0.816 & $0.27(1.12)$ & $-1.93-2.48$ & 0.806 \\
\hline Week of pregnancy & 353 & $-0.04(0.05)$ & $-0.15-0.07$ & 0.470 & $-0.04(0.05)$ & $-0.15-0.07$ & 0.471 \\
\hline \multicolumn{8}{|l|}{ Health-related concerns } \\
\hline Level of concern about: $(1-5)$ & 353 & & & & & & \\
\hline COVID-19 symptoms and complications & & $2.68(0.49)$ & $1.70-3.66$ & $<0.001$ & $2.70(0.49)$ & $1.72-3.67$ & $<0.001$ \\
\hline Contagion and consequences on the baby & & $1.85(0.59)$ & $0.70-3.01$ & 0.002 & $1.87-0.59$ & $0.71-3.03$ & 0.002 \\
\hline Restrictive measures and isolation & & $1.66(0.45)$ & $0.76-2.56$ & $<0.001$ & $1.66(0.46)$ & $0.76-2.57$ & $<0.001$ \\
\hline Delivery & & $2.09(0.50)$ & $1.09-3.08$ & $<0.001$ & $2.08(0.59)$ & $1.08-3.08$ & $<0.001$ \\
\hline Postpartum and breastfeeding & & $1.79(0.49)$ & $0.82-2.77$ & $<0.001$ & $1.81(0.49)$ & $0.83-2.78$ & $<0.001$ \\
\hline \multicolumn{8}{|l|}{ Health information-related factors } \\
\hline Degree of information you have about: $(1-5)$ & 353 & & & & & & \\
\hline COVID-19 symptoms and complications & & $-1.39(0.42)$ & $-2.23-0.56$ & 0.001 & $-1.41(0.42)$ & $-2.24-0.58$ & 0.001 \\
\hline Contagion and consequences on the baby & & $-1.35(0.42)$ & $-2.19-0.52$ & 0.001 & $-1.37(0.42)$ & $-2.21-0.54$ & 0.001 \\
\hline Restrictive measures and isolation & & $-1.13(0.40)$ & $-1.93-0.33$ & 0.005 & $-1.12(0.40)$ & $-1.92-0.32$ & 0.001 \\
\hline Delivery & & $-1.15(0.40)$ & $-1.94-0.36$ & 0.004 & $-1.16(0.40)$ & $-1.95-0.37$ & 0.004 \\
\hline Postpartum and breastfeeding & & $-1.66(0.42)$ & $-2.49-0.83$ & $<0.001$ & $-1.68(0.42)$ & $-2.51-0.85$ & $<0.001$ \\
\hline $\begin{array}{l}\text { Have obtained information about COVID-19 } \\
\text { during pregnancy from: }\end{array}$ & 353 & & & & & & \\
\hline Health professionals & & $0.57(1.15)$ & $-1.67-2.83$ & 0.616 & $0.62(1.15)$ & $-1.63-2.88$ & 0.587 \\
\hline Hospital obstetric newsletter & & $-0.18(1.39)$ & $-2.91-2.54$ & 0.894 & $-0.17(1.39)$ & $-2.90-2.55$ & 0.899 \\
\hline Hospital obstetric web page & & $-1.55(1.52)$ & $-4.53-1.42$ & 0.307 & $-1.55(1.52)$ & $-4.54-1.43$ & 0.308 \\
\hline Official sources of health information & & $-1.20(1.27)$ & $-3.69-1.28$ & 0.345 & $-1.24-1.27$ & $-3.74-1.24$ & 0.327 \\
\hline Internet & & $1.84(1.23)$ & $-0.57-4.27$ & 0.136 & $1.77(1.24)$ & $-0.65-4.21$ & 0.152 \\
\hline Social networks & & $2.17(1.18)$ & $-0.14-4.49$ & 0.067 & $2.09(1.19)$ & $-0.24-4.43$ & 0.079 \\
\hline Family and friends & & $0.73(1.39)$ & $-1.99-3.46$ & 0.598 & $0.68(1.39)$ & $-2.04-3.41$ & 0.622 \\
\hline $\mathrm{Tv}$ & & $2.98(1.29)$ & $0.45-5.52$ & 0.021 & $2.92(1.30)$ & $0.36-5.48$ & 0.025 \\
\hline $\begin{array}{l}\text { Health professional who has provided the } \\
\text { most information: }\end{array}$ & 353 & & & & & & \\
\hline Gynecologist & & $0.38(1.10)$ & $-1.79-2.55$ & 0.731 & $0.34(1.10)$ & $-1.82-2.51$ & 0.756 \\
\hline Midwife & & $-3.05(1.36)$ & $-5.74-0.37$ & 0.025 & $-3.05(1.36)$ & $-5.73-0.37$ & 0.025 \\
\hline Nurse & & $-0.90(2.83)$ & $-6.45-4.64$ & 0.749 & $-1.10(2.84)$ & $-6.68-4.47$ & 0.698 \\
\hline Other & & $1.92(1.63)$ & $-1.28-5.13$ & 0.239 & $2.06(1.64)$ & $-1.16-5.29$ & 0.210 \\
\hline $\begin{array}{l}\text { Satisfaction with information provided by } \\
\text { health professionals }(1-5)\end{array}$ & 353 & $-1.39(0.45)$ & $-2.28-0.50$ & 0.002 & $-1.41(0.45)$ & $-2.30-0.52$ & 0.002 \\
\hline $\begin{array}{l}\text { Satisfaction with empathy showed by } \\
\text { professionals when informed }(1-5)\end{array}$ & 353 & $-2.01(0.43)$ & $-2.87-1.15$ & $<0.001$ & $-2.02(0.43)$ & $-2.88-1.16$ & $<0.001$ \\
\hline
\end{tabular}

Bold: $\mathrm{p} \leq 0.05$. Adjusted model: Analyses were adjusted for medical positive COVID-19 test and age. $\beta$, unstandardized coefficient.

a Due COVID-19.

\subsection{Socioeconomic and Demographic Factors}

Reduced working hours $(\beta=4.07,1.35(\mathrm{SE}), p=0.003)$ and reduced income $(\beta=2.66$, $1.19(\mathrm{SE}), p=0.025)$ due to the COVID-19 pandemic was related to a higher STAI-S score. However, being a separated or divorced woman $(\beta=-8.33,2.79(\mathrm{SE}), p=0.003)$ was related to a lower STAI-S score.

\subsection{Health-Related Concerns}

A one-unit increase in the level of concern (1\%) about COVID-19 symptoms and complications of the sickness $(\beta=2.70,0.49(\mathrm{SE}), p<0.001)$, contagion and consequences for the baby $(\beta=1.87,0.59(\mathrm{SE}), p=0.002)$, restrictive measures and isolation adopted against COVID-19 ( $\beta=1.66,0.46(\mathrm{SE}), p<0.001)$, delivery $(\beta=2.080 .59(\mathrm{SE}), p<0.001)$ and 
postpartum and breastfeeding ( $\beta=1.81,0.49$ (SE), $p<0.001)$ was associated with a higher STAI-S score.

\subsection{Health Information-Related Factors}

Obtaining information from TV ( $\beta=2.92,1.30$ (SE), $p=0.025)$ was related to a higher STAI-S score. However, being informed to a greater extent by a midwife $(\beta=-3.05$, $1.36(\mathrm{SE}), p=0.025$ ) was related to a lower STAI-S score. A one-unit increase in the degree of information obtained about COVID-19 symptoms and complications of the sickness ( $\beta=-1.41,0.42$ (SE), $p=0.001)$, contagion and consequences on the baby $(\beta=-1.37$, 0.42 (SE), $p=0.001$ ), restrictive measures and isolation adopted against COVID-19 ( $\beta=-1.12$, 0.40 (SE), $p<0.001$ ), delivery $(\beta=-1.16,0.40(\mathrm{SE}), p=0.004)$ and postpartum and breastfeeding ( $\beta=-1.68,0.42$ (SE), $p<0.001$ ) was related to a lower STAI-S score. Finally, a one-unit increase in the level of satisfaction with the information provided by the health professional $(\beta=-1.41,0.45$ (SE), $p=0.002)$ and the empathy shown by the professional when informing ( $\beta=-2.02,0.43$ (SE), $p<0.001$ ) was associated to a lower STAI-S score.

\section{Discussion}

As previously mentioned, the objective of the present study was to identify those socioeconomic, demographic, health-related and information management factors and concerns that may influence the anxiety level of pregnant women during the COVID-19 pandemic. The results obtained in the study provide important information about those factors that increase anxiety and those that could help to mitigate it. According to our results, reduced working hours and reduced income due to the COVID-19 pandemic were related to higher anxiety levels. These results are congruent with other studies carried out previously, in which the vulnerability of this group of women has been evidenced [32,54]. While economic and employment uncertainty has proven to be a risk factor for mental health in the general population [13,55-58], it may be even more so in this group. Specifically, it could be hypothesized that, while the stress and pressure associated with new economic responsibilities is often a risk factor for the mental health of pregnant women under normal circumstances [59-61], one could expect it to be to be even more so in conditions of economic uncertainty and instability such as those caused by the COVID-19 outbreak. Given the peculiarity of the COVID-19 pandemic, the absence of similar baseline situations and the abruptness of the social changes made, the responsibility of bringing a new life into the world may be increased, in a context in which one's working hours and salary have been affected. After all, it is known that fear of job loss has been a recurrent concern in pregnant women, significantly increasing levels of stress and anxiety [46].

According to this study's results, the level of concern about COVID-19 symptoms and complications of the sickness, contagion and consequences for the baby, restrictive measures and isolation adopted against COVID-19, delivery, postpartum and breastfeeding were also associated with higher anxiety levels. While early medical advice was skeptical about the risk of COVID-19 transmission between new mothers and their newborns, subsequent studies have shown that, with the necessary precautions, breastfeeding infants is safe $[62,63]$. However, several studies have shown that, despite evidence that breast feeding is safe, pregnant and new mothers continue to worry about risk of contagion and infection of the baby to the extent that many women have decided not to breastfeed their children $[33,34]$. While this study does not provide data on women who have decided to forgo breastfeeding, it is known that the fear of breastfeeding has significantly increased anxiety levels in pregnant women. Uncertainty, fear, and the amount of contradictory information on the subject may have precipitated these states of anxiety among pregnant women $[50,64,65]$. In addition, face-to-face professional support for breastfeeding was reduced or cancelled in many countries, which may have contributed to increased anxiety levels regarding breastfeeding. Concretely, it has been found that mothers with lower educational levels, more challenging living circumstances and from minority ethnic groups were more likely to be affected by the situation and stop breastfeeding [66]. 
The absence or restriction of professional support in the case of breastfeeding can be extended to pregnancy, childbirth and postpartum $[47,64,67,68]$. For instance, other studies have found that discontinuing face-to-face prenatal visits and making new plans to avoid delivering in a hospital may have increased anxiety during the pandemic $[46,47]$. In addition, lack of ultrasound results and other regular health exams may have also negatively contributed to women's perceived control, as has been observed in studies prior to the pandemic [48]. Similarly, other authors have hypothesized that a greater locus of control among pregnant women (for instance, by planning childbirth at home) may have helped to reduce anxiety [46].

Finally, concern due to the extensive restrictive measures and social isolation mandated by governments should be highlighted as a risk factor associated with anxiety in pregnant women. Access to public places and transportation has also been a major concern for pregnant women, as reported in other studies [47]. If isolation measures have been shown to damage the mental health of the general population, the same phenomenon has logically been observed in pregnant women $[38,65,69,70]$. Loneliness and rumination resulting from the lockdown may have been exacerbated by fear of not being able to access health services if the need arose $[46,47]$, as well as by a rise in other threatening factors such as deterioration of relationships with other co-living family members and increased gender-based violence, factors that have been documented by other authors [71-73].

In terms of protective factors for anxiety, according to our results, being a separated or divorced woman and being informed to a greater extent by a midwife were related to lower anxiety levels. An increase in the degree of information obtained about COVID-19 symptoms and complications of the sickness, contagion and consequences on the baby, restrictive measures and isolation adopted against COVID-19, delivery, postpartum and breastfeeding were related to decreased anxiety levels. An increase in the satisfaction level with information provided by the health professional and the empathy shown by the professional, while still informing, were also associated to reduced anxiety scores. These results are in line with previous studies emphasizing the importance of information received during COVID-19 for people's mental health [15,74,75]. According to these studies, receiving sufficient information regarding the virus was a protective factor in the appearance of symptoms of depression, anxiety and post-traumatic stress disorders [15]. However, the use of the Internet (unofficial web-based media) as a source of information during the COVID-19 was significantly associated with poorer psychological well-being and mental health $[71,76]$. Therefore, the quality of the information received is a key aspect for determining its impact on mental health [71].

Satisfaction with the information received could also play an important role [77]. An empathetic relationship with healthcare professionals has been proven to benefit patients in numerous research studies [72,78]. However, the COVID-19 pandemic has once again brought these findings to the forefront $[73,74]$. Empathetic and quality communication with the health professional increases satisfaction and adherence to treatment, and improves objective and subjective outcomes among patients [72], especially in such a difficult context as COVID-19 [75].

Finally, it is worth noting that being single or divorced was found to be a protective factor for anxiety. Although loneliness has been identified as a risk factor for mental health during the COVID-19 outbreak [79], other studies point out that marital conflict and gender-based violence have threatened women's well-being $[65,80]$, which may help contextualize the findings.

The study presents some limitations that must be taken into account when interpreting the results. Although all questionnaires were carefully chosen and all are valid and reliable, the variables are self-reported, which could bias the inherent quality of the data. In addition, the absence of specific measures to identify and assess mental health during COVID-19 has been a limitation, and researchers have had to rely on already validated, but perhaps not as specific, measures. Unmeasured covariates may have resulted in residual confounding. The cross-sectional nature of the data cannot infer causation; we can only report associations 
between mental health indicators and social, demographic and economic factors. The sample considered in this study is not representative of the general Spanish population. Thus, the results of the present study cannot be generalizable to the general population. Finally, future longitudinal studies should be carried out to extend the cross-sectional perspective examined in this study.

\section{Conclusions}

In conclusion, the most vulnerable future mothers in terms of anxiety levels are those with reduced working hours and income due to the COVID-19 pandemic, those with a higher level of concern and who had access to a lesser degree of information about COVID19 (symptoms and complications, contagion and consequences on the baby, restrictive measures and isolation, delivery, postpartum and breastfeeding), as well as pregnant women who have obtained information about COVID-19 during pregnancy from TV. By contrast, being a separated or divorced woman, being informed in a satisfactory manner by an empathetic professional, especially by a mid-wife, was related to more favorable anxiety levels.

Since maternal mental health problems are associated with short-term and longterm risks for the mothers' health and their children's overall development, these results must be seriously considered. As practical implications of these findings, competent health systems should include this information when designing procedures to deal with current and future pandemics. Health authorities, counselors and obstetric care providers should take into account the relevance of the health information provided on the mental health of an already vulnerable group in a pandemic context. Therefore, appropriate protocols should be implemented in order to ensure that adequately trained and empathetic professionals provide sufficient quality information, thus preventing high levels of anxiety in pregnant women.

Author Contributions: S.E.-G. was an investigator of the study and revised the article. M.C.-G. was an investigator of the study and revised the article. J.L.G.-P. was an investigator of the study and revised the article. M.Á.-N. was an investigator of the study and revised the article. L.E.-G. was an investigator of the study and revised the article. All authors have read and agreed to the published version of the manuscript.

Funding: This research received no external funding.

Institutional Review Board Statement: The protocol for the present study obtained approval from the Ethics Committee of the Jiménez Díaz Foundation Hospital (E0070-20_HUQM).

Informed Consent Statement: All institutions and participants were informed of the purpose and intent of the study and provided written consent. Similarly, anonymity of each of the participants was ensured.

Data Availability Statement: The data presented in this study are available on request from the corresponding author.

Acknowledgments: We acknowledge all those who generously accepted to participate in our study, giving us the opportunity to make the difficult situation they were living in visible. The authors are especially grateful to Catherine Dunn, for her invaluable work editing the English of this manuscript.

Conflicts of Interest: The authors declare no conflict of interest.

\section{References}

1. Garfin, D.R.; Silver, R.C.; Holman, E.A. The novel coronavirus (COVID-2019) outbreak: Amplification of public health consequences by media exposure. Health Psychol. 2020, 39, 355-357. [CrossRef] [PubMed]

2. Bambra, C.; Riordan, R.; Ford, J.; Matthews, F. The COVID-19 pandemic and health inequalities. J. Epidemiol. Community Health 2020, 74, 964-968. [CrossRef]

3. Kumar, A.; Nayar, K.R. COVID 19 and its mental health consequences. J. Ment. Health 2020, 180, 817-818. [CrossRef] [PubMed]

4. Vindegaard, N.; Benros, M.E. COVID-19 pandemic and mental health consequences: Systematic review of the current evidence. Brain Behav. Immun. 2020, 89, 531-542. [CrossRef] [PubMed] 
5. Galea, S.; Merchant, R.M.; Lurie, N. The mental health consequences of COVID-19 and physical distancing: The need for prevention and early intervention. JAMA Intern. Med. 2020, 180, 817-818. [CrossRef]

6. Giuntella, O.; Hyde, K.; Saccardo, S.; Sadoff, S. Lifestyle and mental health disruptions during Covid-19. Proc. Natl. Acad. Sci. USA 2021, 118. [CrossRef]

7. Romero-Blanco, C.; Rodríguez-Almagro, J.; Onieva-Zafra, M.D.; Parra-Fernández, M.L.; Prado-Laguna, M.D.C.; HernándezMartínez, A. Physical activity and sedentary lifestyle in university students: Changes during confinement due to the Covid-19 pandemic. Int. J. Environ. Res. Public Health 2020, 17, 6567. [CrossRef]

8. Zheng, C.; Huang, W.Y.; Sheridan, S.; Sit, C.H.-P.; Chen, X.-K.; Wong, S.H.-S. COVID-19 pandemic brings a sedentary lifestyle in young adults: A cross-sectional and longitudinal study. Int. J. Environ. Res. Public Health 2020, 17, 6035. [CrossRef]

9. Banerjee, D.; Rai, M. Social Isolation in COVID-19: The Impact of Loneliness; SAGE Publications Sage UK: London, UK, 2020.

10. Brooke, J.; Jackson, D. Older People and COVID-19: Isolation, Risk and Ageism; Wiley Online Library: Hoboken, NJ, USA, 2020.

11. Pancani, L.; Marinucci, M.; Aureli, N.; Riva, P. Forced social isolation and mental health: A study on 1006 Italians under COVID-19 quarantine. Front. Psychol. 2020, 12, 1540.

12. Usher, K.; Bhullar, N.; Jackson, D. Life in the Pandemic: Social Isolation and Mental Health; Wiley Online Library: Hoboken, NJ, USA, 2020.

13. Esteban-Gonzalo, S.; González-Pascual, J.L.; Caballero-Galilea, M.; Esteban-Gonzalo, L. Psychosocial Correlates of Mental Health and Well-Being During the COVID-19: The Spanish Case. Front. Psychol. 2020, 11, 3197. [CrossRef] [PubMed]

14. Rodríguez-Rey, R.; Garrido-Hernansaiz, H.; Collado, S. Psychological impact and associated factors during the initial stage of the coronavirus (COVID-19) pandemic among the general population in Spain. Front. Psychol. 2020, 11, 1540. [CrossRef]

15. González-Sanguino, C.; Ausín, B.; Castellanos, M.Á.; Saiz, J.; López-Gómez, A.; Ugidos, C.; Muñoz, M. Mental health consequences during the initial stage of the 2020 Coronavirus pandemic (COVID-19) in Spain. Brain Behav. Immun. 2020, 87, 172-176. [CrossRef]

16. Frank, P.; Iob, E.; Steptoe, A.; Fancourt, D. Trajectories of depressive symptoms among vulnerable groups in the UK during the COVID-19 pandemic. medRxiv 2020. [CrossRef]

17. Domínguez-Salas, S.; Gómez-Salgado, J.; Andrés-Villas, M.; Díaz-Milanés, D.; Romero-Martín, M.; Ruiz-Frutos, C. Psychoemotional approach to the psychological distress related to the COVID-19 pandemic in Spain: A cross-sectional observational study. In Healthcare; Multidisciplinary Digital Publishing Institute: Basel, Switzerland, 2020; p. 190.

18. Almeida, M.; Shrestha, A.D.; Stojanac, D.; Miller, L.J. The impact of the COVID-19 pandemic on women's mental health. Arch. Women's Ment. Health 2020, 23, 1-8. [CrossRef]

19. Rodríguez-Rey, R.; Garrido-Hernansaiz, H.; Collado, S. Psychological impact of COVID-19 in Spain: Early data report. Psychol. Trauma: Theory Res. Pract. Policy 2020, 12, 550. [CrossRef] [PubMed]

20. Wang, C.; Pan, R.; Wan, X.; Tan, Y.; Xu, L.; Ho, C.S.; Ho, R.C. Immediate psychological responses and associated factors during the initial stage of the 2019 coronavirus disease (COVID-19) epidemic among the general population in China. Int. J. Environ. Res. Public Health 2020, 17, 1729. [CrossRef] [PubMed]

21. Liu, N.; Zhang, F.; Wei, C.; Jia, Y.; Shang, Z.; Sun, L.; Wu, L.; Sun, Z.; Zhou, Y.; Wang, Y. Prevalence and predictors of PTSS during COVID-19 outbreak in China hardest-hit areas: Gender differences matter. Psychiatry Res. 2020, 287, 112921. [CrossRef] [PubMed]

22. Campbell, A.M. An increasing risk of family violence during the Covid-19 pandemic: Strengthening community collaborations to save lives. Forensic Sci. Int. Rep. 2020, 2, 100089. [CrossRef]

23. Power, K. The COVID-19 pandemic has increased the care burden of women and families. Sustain. Sci. Pract. Policy 2020, 16, 67-73. [CrossRef]

24. Carli, L.L. Women, Gender equality and COVID-19. Gend. Manag. Int. J. 2020. [CrossRef]

25. Malik, S.; Naeem, K. Impact of COVID-19 Pandemic on Women: Health, Livelihoods \& Domestic Violence; Sustainable Development Policy Institute: Islamabad, Pakistan, 2020.

26. O'Hara, M.W.; Wisner, K.L. Perinatal mental illness: Definition, description and aetiology. Best Pract. Res. Clin. Obstet. Gynaecol. 2014, 28, 3-12. [CrossRef]

27. Fairbrother, N.; Young, A.H.; Janssen, P.; Antony, M.M.; Tucker, E. Depression and anxiety during the perinatal period. BMC Psychiatry 2015, 15, 1-9. [CrossRef]

28. Meltzer-Brody, S.; Stuebe, A. The long-term psychiatric and medical prognosis of perinatal mental illness. Best Pract. Res. Clin. Obstet. Gynaecol. 2014, 28, 49-60. [CrossRef]

29. Misra, D.P.; Guyer, B.; Allston, A. Integrated perinatal health framework: A multiple determinants model with a life span approach. Am. J. Prev. Med. 2003, 25, 65-75. [CrossRef]

30. Saade, G.R. Pregnancy as a Window to Future Health. Obstet Gynecol. 2009, 114, 958-960. [CrossRef]

31. Zeng, L.-N.; Chen, L.-G.; Yang, C.-M.; Zeng, L.-P.; Zhang, L.-Y.; Peng, T.-M. Mental health care for pregnant women in the COVID-19 outbreak is urgently needed. Women Birth 2020. [CrossRef] [PubMed]

32. Thapa, S.B.; Mainali, A.; Schwank, S.E.; Acharya, G. Maternal Mental Health in the Time of the COVID-19 Pandemic; Wiley Online Library: Hoboken, NJ, USA, 2020.

33. López-Morales, H.; Del Valle, M.V.; Canet-Juric, L.; Andrés, M.L.; Galli, J.I.; Poó, F.; Urquijo, S. Mental health of pregnant women during the COVID-19 pandemic: A longitudinal study. Psychiatry Res. 2021, 295, 113567. [CrossRef] [PubMed] 
34. Kotabagi, P.; Fortune, L.; Essien, S.; Nauta, M.; Yoong, W. Anxiety and depression levels among pregnant women with COVID-19. Acta Obstet. Gynecol. Scand. 2020, 99, 953-954. [CrossRef]

35. Caparros-Gonzalez, R.A.; Alderdice, F. The COVID-19 pandemic and perinatal mental health. J. Reprod. Infant Psychol. 2020, 38, 223-225. [CrossRef] [PubMed]

36. Tomori, C.; Gribble, K.; Palmquist, A.E.; Ververs, M.T.; Gross, M.S. When separation is not the answer: Breastfeeding mothers and infants affected by COVID-19. Matern. Child. Nutr. 2020, 16, e13033. [CrossRef]

37. Shonkoff, J.P.; Garner, A.S. Committee on psychosocial aspects of child and family health committee on early childhood, adoption, and dependent care section on developmental and behavioral pediatrics the lifelong effects of early childhood adversity and toxic stress. Pediatrics 2012, 129, e232-e246. [CrossRef]

38. Brooks, S.K.; Dunn, R.; Amlôt, R.; Rubin, G.J.; Greenberg, N. A systematic, thematic review of social and occupational factors associated with psychological outcomes in healthcare employees during an infectious disease outbreak. J. Occup. Environ. Med. 2018, 60, 248-257. [CrossRef]

39. Ceulemans, M.; Hompes, T.; Foulon, V. Mental health status of pregnant and breastfeeding women during the COVID-19 pandemic: A call for action. Int. J. Gynecol. Obstet. 2020, 151, 146-147. [CrossRef]

40. Ali, N.A.; Feroz, A.S. Maternal mental health amidst the COVID-19 pandemic. Asian J. Psychiatry 2020, 54, 102261. [CrossRef] [PubMed]

41. Wu, Y.; Zhang, C.; Liu, H.; Duan, C.; Li, C.; Fan, J.; Li, H.; Chen, L.; Xu, H.; Li, X. Perinatal depressive and anxiety symptoms of pregnant women along with COVID-19 outbreak in China. Am. J. Obstet. Gynecol. 2020. [CrossRef]

42. Leigh-Hunt, N.; Bagguley, D.; Bash, K.; Turner, V.; Turnbull, S.; Valtorta, N.; Caan, W. An overview of systematic reviews on the public health consequences of social isolation and loneliness. Public Health 2017, 152, 157-171. [CrossRef] [PubMed]

43. Roesch, E.; Amin, A.; Gupta, J.; García-Moreno, C. Violence Against Women during Covid-19 Pandemic Restrictions; British Medical Journal Publishing Group: London, UK, 2020.

44. Sánchez, O.R.; Vale, D.B.; Rodrigues, L.; Surita, F.G. Violence against women during the COVID-19 pandemic: An integrative review. Int. J. Gynecol. Obstet. 2020, 151, 180-187. [CrossRef]

45. World Health Organization. COVID-19 and Violence against Women: What the Health Sector/System Can Do, 7 April 2020; World Health Organization: Geneva, Switzerland, 2020.

46. Dong, H.; Hu, R.; Lu, C.; Huang, D.; Cui, D.; Huang, G.; Zhang, M. Investigation on the mental health status of pregnant women in China during the Pandemic of COVID-19. Arch. Gynecol. Obstet. 2021, 303, 463-469. [CrossRef]

47. Yang, X.; Song, B.; Wu, A.; Mo, P.K.; Di, J.; Wang, Q.; Lau, J.T.; Wang, L. Social, Cognitive, and eHealth Mechanisms of COVID19-Related Lockdown and Mandatory Quarantine That Potentially Affect the Mental Health of Pregnant Women in China: Cross-Sectional Survey Study. J. Med. Internet Res. 2021, 23, e24495. [CrossRef]

48. Preis, H.; Mahaffey, B.; Heiselman, C.; Lobel, M. Vulnerability and resilience to pandemic-related stress among US women pregnant at the start of the COVID-19 pandemic. Soc. Sci. Med. 2020, 266, 113348. [CrossRef]

49. Moyer, C.A.; Compton, S.D.; Kaselitz, E.; Muzik, M. Pregnancy-related anxiety during COVID-19: A nationwide survey of 2740 pregnant women. Arch. Women's Ment. Health 2020, 23, 1-9. [CrossRef]

50. Taubman-Ben-Ari, O.; Chasson, M.; Abu Sharkia, S.; Weiss, E. Distress and anxiety associated with COVID-19 among Jewish and Arab pregnant women in Israel. J. Reprod. Infant Psychol. 2020, 38, 340-348. [CrossRef]

51. Harpel, T.S. Fear of the unknown: Ultrasound and anxiety about fetal health. Health 2008, 12, 295-312. [CrossRef]

52. Perzow, S.E.; Hennessey, E.-M.P.; Hoffman, M.C.; Grote, N.K.; Davis, E.P.; Hankin, B.L. Mental health of pregnant and postpartum women in response to the COVID-19 pandemic. J. Affect. Disord. Rep. 2021, 4, 100123. [CrossRef] [PubMed]

53. Guillén-Riquelme, A.; Buela-Casal, G. Meta-analysis of group comparison and meta-analysis of reliability generalization of the State-Trait Anxiety Inventory Questionnaire (STAI). Rev. Española Salud Pública 2014, 88, 101-112. [CrossRef]

54. Guillén-Riquelmeé, A.; Buela-Casal, G. Actualización psicométrica y funcionamiento diferencial de los items en el State Trait Anxiety Inventory (STAI). Psicothema 2011, 23, 510-515.

55. Tenenbaum, G.; Furst, D.; Weingarten, G. A statistical reevaluation of the STAI anxiety questionnaire. J. Clin. Psychol. 1985, 41, 239-244. [CrossRef]

56. INE. Available online: https:/ / www.ine.es/ (accessed on 10 July 2020).

57. Holmes, E.A.; O'Connor, R.C.; Perry, V.H.; Tracey, I.; Wessely, S.; Arseneault, L.; Ballard, C.; Christensen, H.; Silver, R.C.; Everall, I. Multidisciplinary research priorities for the COVID-19 pandemic: A call for action for mental health science. Lancet Psychiatry 2020, 7, 547-560. [CrossRef]

58. Donnelly, R.; Farina, M.P. How do state policies shape experiences of household income shocks and mental health during the COVID-19 pandemic? Soc. Sci. Med. 2021, 269, 113557. [CrossRef]

59. Guo, Y.; Cheng, C.; Zeng, Y.; Li, Y.; Zhu, M.; Yang, W.; Xu, H.; Li, X.; Leng, J.; Monroe-Wise, A. Mental health disorders and associated risk factors in Quarantined adults during the COVID-19 outbreak in China: Cross-sectional study. J. Med. Internet Res. 2020, 22, e20328. [CrossRef] [PubMed]

60. Kämpfen, F.; Kohler, I.V.; Ciancio, A.; Bruine de Bruin, W.; Maurer, J.; Kohler, H.-P. Predictors of mental health during the Covid-19 pandemic in the US: Role of economic concerns, health worries and social distancing. PLoS ONE 2020, 15, e0241895. [CrossRef] 
61. Wilson, J.M.; Lee, J.; Fitzgerald, H.N.; Oosterhoff, B.; Sevi, B.; Shook, N.J. Job insecurity and financial concern during the COVID-19 pandemic are associated with worse mental health. J. Occup. Environ. Med. 2020, 62, 686-691. [CrossRef] [PubMed]

62. Podvornik, N.; Velikonja, V.G.; Praper, P. Depression and anxiety in women during pregnancy in Slovenia. Slov. J. Public Health 2015, 54, 45. [CrossRef] [PubMed]

63. Glazier, R.; Elgar, F.; Goel, V.; Holzapfel, S. Stress, social support, and emotional distress in a community sample of pregnant women. J. Psychosom. Obstet. Gynecol. 2004, 25, 247-255. [CrossRef]

64. Zanardo, V.; Manghina, V.; Giliberti, L.; Vettore, M.; Severino, L.; Straface, G. Psychological impact of COVID-19 quarantine measures in northeastern Italy on mothers in the immediate postpartum period. Int. J. Gynecol. Obstet. 2020, 150, 184-188. [CrossRef] [PubMed]

65. Brown, A.; Shenker, N. Experiences of breastfeeding during COVID-19: Lessons for future practical and emotional support. Matern. Child. Nutr. 2021, 17, e13088. [CrossRef]

66. Biaggi, A.; Conroy, S.; Pawlby, S.; Pariante, C.M. Identifying the women at risk of antenatal anxiety and depression: A systematic review. J. Affect. Disord. 2016, 191, 62-77. [CrossRef] [PubMed]

67. Pereira, A.; Cruz-Melguizo, S.; Adrien, M.; Fuentes, L.; Marin, E.; Forti, A.; Perez-Medina, T. Breastfeeding mothers with COVID-19 infection: A case series. Int. Breastfeed. J. 2020, 15, 1-8. [CrossRef] [PubMed]

68. Marín Gabriel, M.A.; Cuadrado, I.; Álvarez Fernández, B.; González Carrasco, E.; Alonso Díaz, C.; Llana Martín, I.; Sánchez, L.; Olivas, C.; de Las Heras, S.; Criado, E. Multicentre Spanish study found no incidences of viral transmission in infants born to mothers with COVID-19. Acta Paediatr. 2020, 109, 2302-2308. [CrossRef]

69. Derya, Y.A.; Altiparmak, S.; Emine, A.; GÖkbulut, N.; Yilmaz, A.N. Pregnancy and birth planning during COVID-19: The effects of tele-education offered to pregnant women on prenatal distress and pregnancy-related anxiety. Midwifery 2021, 92, 102877.

70. Ravaldi, C.; Wilson, A.; Ricca, V.; Homer, C.; Vannacci, A. Pregnant women voice their concerns and birth expectations during the COVID-19 pandemic in Italy. Women Birth 2020, 34, 335-343. [CrossRef]

71. García-Fernández, L.; Romero-Ferreiro, V.; Padilla, S.; David López-Roldán, P.; Monzó-García, M.; Rodriguez-Jimenez, R. Gender differences in emotional response to the COVID-19 outbreak in Spain. Brain Behav. 2021, 11, e01934. [CrossRef] [PubMed]

72. Davis-Floyd, R.; Gutschow, K.; Schwartz, D.A. Pregnancy, birth and the COVID-19 pandemic in the United States. Med. Anthropol. 2020, 39, 413-427. [CrossRef]

73. Bhargava, S.; Sarkar, R.; Kroumpouzos, G. Mental distress in dermatologists during COVID-19 pandemic: Assessment and risk factors in a global, cross-sectional study. Dermatol. Ther. 2020, 33, e14161. [CrossRef]

74. Ko, N.-Y.; Lu, W.-H.; Chen, Y.-L.; Li, D.-J.; Wang, P.-W.; Hsu, S.-T.; Chen, C.-C.; Lin, Y.-H.; Chang, Y.-P.; Yen, C.-F. COVID-19-related information sources and psychological well-being: An online survey study in Taiwan. Brain Behav. Immun. 2020, 87, 153-154. [CrossRef] [PubMed]

75. Milne, S.J.; Corbett, G.A.; Hehir, M.P.; Lindow, S.W.; Mohan, S.; Reagu, S.; Farrell, T.; O'Connell, M.P. Effects of isolation on mood and relationships in pregnant women during the covid-19 pandemic. Eur. J. Obstet. Gynecol. Reprod. Biol. 2020, 252, 610-611. [CrossRef]

76. Durankuş, F.; Aksu, E. Effects of the COVID-19 pandemic on anxiety and depressive symptoms in pregnant women: A preliminary study. J. Matern. Fetal Neonatal Med. 2020, 1-7. [CrossRef]

77. Davenport, M.H.; Meyer, S.; Meah, V.L.; Strynadka, M.C.; Khurana, R. Moms are not ok: COVID-19 and maternal mental health. Front. Glob. Women's Health 2020, 1, 1. [CrossRef]

78. Mittal, S.; Singh, T. Gender-based violence during COVID-19 pandemic: A mini-review. Front. Glob. Women's Health 2020, 1, 4. [CrossRef]

79. Pan, Y.; Xin, M.; Zhang, C.; Dong, W.; Fang, Y.; Wu, W.; Li, M.; Pang, J.; Zheng, Z.; Wang, Z. Associations of mental health and personal preventive measure compliance with exposure to COVID-19 information during work resumption following the COVID-19 outbreak in China: Cross-sectional survey study. J. Med. Internet Res. 2020, 22, e22596. [CrossRef]

80. Ho, C.S.; Chee, C.Y.; Ho, R.C. Mental health strategies to combat the psychological impact of COVID-19 beyond paranoia and panic. Ann. Acad Med. Singap. 2020, 49, 1-3. 